\title{
Radical Methylation of Hetero-aromatics by the DMSO-Hydrogen Peroxide Method
}

\author{
ULF RUDQVIST and KURT TORSSELL ${ }^{\mathrm{b} *}$
}

\begin{abstract}
${ }^{a}$ Institute of Organic Chemistry, University of Stockholm, Sandaisgatan 2, S-113 27 Stockholm, Sweden, and 'Department of Organic Chemistry, University of Aarhus, DK-8000 Aarhus C, Denmark
\end{abstract}

\begin{abstract}
The distribution of isomers arising from radical methylation of some substituted hetero-aromatics has been investigated. Methyl radicals were generated by the DMSO-hydrogen peroxide method. The nitro group exhibits strong ortho-directing properties. 2-Nitrothiophene gave mainly the 3-methyl derivative. The other compounds tested gave products in general agreement with earlier experience of the radical substitution of hetero-aromatics. In the furan series, an unusual displacement of the nitro group by methyl was discovered.
\end{abstract}

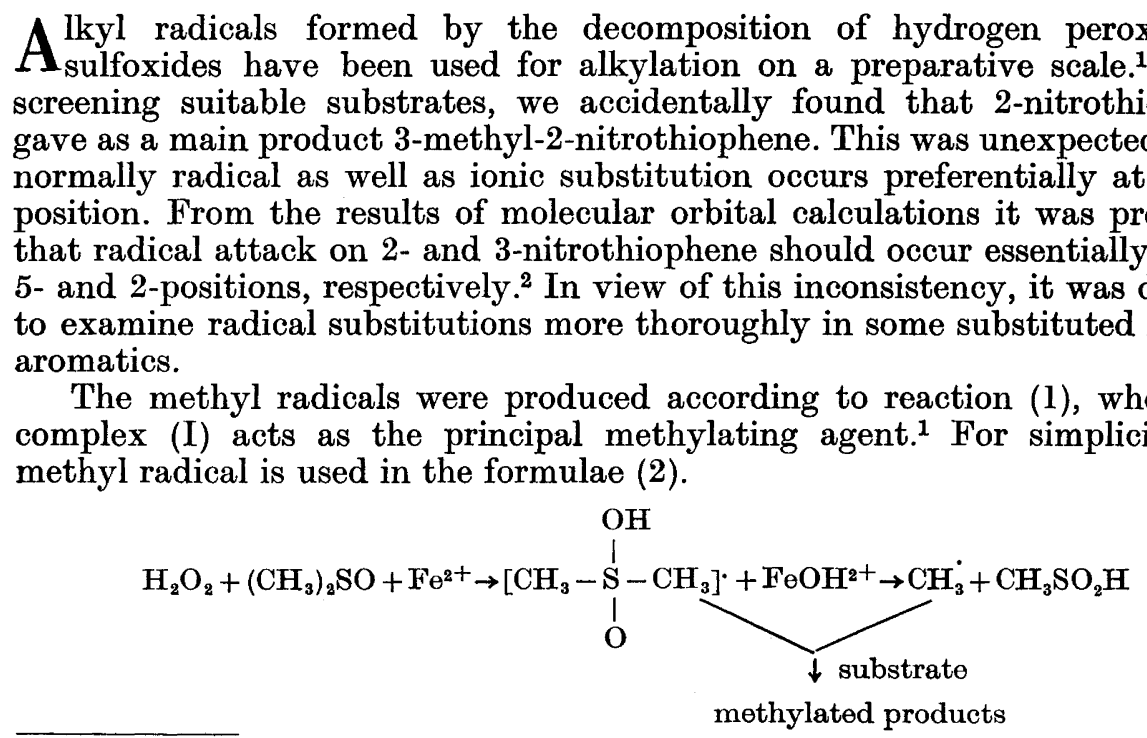

* To whom inquiries should be addressed. 


\section{DISCUSSION AND RESULTS}

Thiophene derivatives. Reinvestigation of the methylation of 2-nitrothiophene confirmed our earlier results. A $40 \%$ yield of 3-methyl-2-nitrothiophene was obtained together with a smaller amount of 3,5-dimethyl-2nitrothiophene, but no trace of 5-methyl-2-nitrothiophene was detected by GLC. The structures of the compounds were proved by NMR and by comparison with authentic samples. They were isolated in pure form by preparative GLC.

The complete absence of the 5-methyl isomer showed that dimethylation proceeded via the 3-methyl derivative.

Phenylation of 2-nitrothiophene with diazonium salt in sulpholane afforded a $10 \%$ yield of a mixture of 3-phenyl-2-nitrothiophene $(74 \%)$ and 5-phenyl-2nitrothiophene $(26 \%)$, again showing that the 3 -position is preferentially attacked. A plausible explanation for this discrepancy between the theoretical and experimental results is that predictions based on the calculations of localization energies do not take into account energies of activation.

3-Nitrothiophene gave as predicted 2-methyl-3-nitrothiophene. ${ }^{2}$

The results from the methylation of 2-thiophene carboxylic acid contrasted sharply with the results of the methylation of the 2-nitro derivative. The isomer distribution found, $14 \%$ of 3-methyl-, $23 \%$ of 5-methyl-, and $6 \%$ of 3,5-dimethyl-2-thiophene carboxylic acid, is in general agreement with predictions ${ }^{2}$ and with previous results from radical substitution in the thiophene series. 3,4

The experimental results are summarized in Table 1.

Furan derivatives. Methylation of 2-nitrofuran, 2,5-dinitrofuran, and 5nitro-2-carbomethoxyfuran gave rise to unexpected products.

The first compound afforded 2-methylfuran (12\%) and 5-methyl-2nitrofuran $(6 \%)$ together with starting material.

The dinitro compound gave 5-methyl-2-nitrofuran $(24 \%)$ as the main product, together with minor amounts (about $5 \%$ ) of a compound tentatively identified as 3,5-dimethyl-2-nitrofuran.

5-Nitro-2-carbomethoxyfuran gave 5-methyl-2-carbomethoxyfuran (15\%), $\gamma$-carbomethoxy- $\alpha, \beta$-dehydro- $\gamma$-valerolactone (12\%), and 4-methyl-5-nitro-2carbomethoxyfuran (4\%).

The reactions represent an unusual displacement of the nitro group by an alkyl radical. It has been reported that aromatic halogens are displaced by cyclohexyl radicals at $105^{\circ}, 5$ and that halogens and the nitro group are substituted in vapor phase halogenation at around $300^{\circ} .{ }^{6}$ The mild radical displacement of the nitro group by methyl in the present case seems, however, to lack precedent.

In view of the strong ortho-directing effect of the nitro group, the minor product $(4 \%)$ in the latter case was assigned the structure indicated, eqn.(2). The structure of the lactone was based on spectroscopic data. The compound showed IR absorptions at $1780-1770 \mathrm{~cm}^{-1}(\mathrm{~s})$ and $1745 \mathrm{~cm}^{-1}(\mathrm{~s})$, characteristic for an $\alpha, \beta$-unsaturated $\gamma$-lactone and a saturated ester. ${ }^{7}$ 
Table 1. Radical substitution of hetero-aromatics with methyl radicals generated by the sulfoxidehydrogen peroxide method. Three moles of $\mathrm{H}_{2} \mathrm{O}_{2}$ were used per mole of substrate.

\begin{tabular}{|c|c|c|c|}
\hline Substrate & $\underset{\text { Temp }}{{ }^{\circ} \mathrm{C}}$ & $\begin{array}{c}\text { Products, NMR-data } a \\
\text { (multiplicity) }\end{array}$ & $\underset{\%}{\text { Yield }^{b}}$ \\
\hline 2-Nitrothiophene & $65^{c}$ & $\begin{array}{l}\text { 3-Methyl-2-nitrothiophene } \\
2.65(\mathrm{~s}), \mathrm{CH}_{3} ; 6.93(\mathrm{~d}), \mathrm{H}_{4}, \\
J=5.2 ; 7.44(\mathrm{~d}), \mathrm{H}_{5}, J=5.2 \\
\text { 3,5-Dimethyl-2-nitrothiophene } \\
2.48(\mathrm{~s}) \mathrm{CH}_{3} ; 2.56(\mathrm{~s}), \mathrm{CH}_{3} ; \\
6.63(\mathrm{~s}), \mathrm{H}_{4}\end{array}$ & 40 \\
\hline 3-Nitrothiophene & $80^{d}$ & $\begin{array}{l}\text { 2-Methyl-3-nitrothiophene } \\
2.80(\mathrm{~s}), \mathrm{CH}_{3} ; 7.03(\mathrm{~d}), \mathrm{H}_{5}, \\
J=5.2 ; 7.59(\mathrm{~d}), \mathrm{H}_{4}, J=5.2\end{array}$ & 17 \\
\hline 2-Thiophene carboxylic acid & $65^{e}$ & 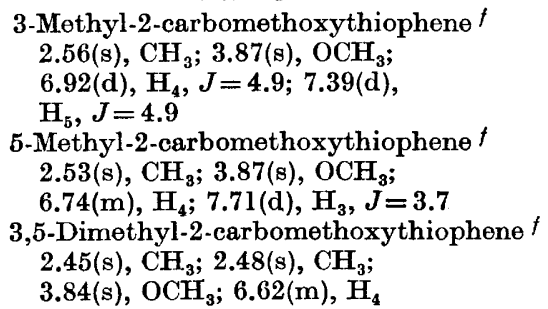 & 23 \\
\hline 2-Nitropyrrole & $30^{g}$ & $\begin{array}{l}\text { 5-Methyl-2-nitropyrrole }{ }^{h} \\
\text { 2.36(s), } \mathrm{CH}_{3} ; 6.06(\mathrm{~m}), \mathrm{H}_{4}, J=3.8^{i} ; \\
\text { 7.08(m), } \mathrm{H}_{3}, J=3.8^{i} \\
\text { 3,5-Dimethyl-2-nitropyrrole } \\
\text { 2.25(s), } \mathrm{CH}_{3} ; 2.35(\mathrm{~s}), \mathrm{CH}_{3} ; \\
\text { 5.94(m), } \mathrm{H}_{4}\end{array}$ & 12 \\
\hline 2-Furoic acid & 65 & 5-Methyl-2-carbomethoxyfuran $t$ & 50 \\
\hline 3-Furoic acid & 75 & $\begin{array}{l}\text { 2-Methyl-3-carbomethoxyfuran } \\
\text { 2.58(s), } \mathrm{CH}_{3} ; 3.83(\mathrm{~s}), \mathrm{OCH}_{3} \\
6.65(\mathrm{~d}), \mathrm{H}_{4}, J=1.8 ; 7.25(\mathrm{~d}) \\
\mathrm{H}_{5}, J=1.8\end{array}$ & 18 \\
\hline 2-Nitrofuran & 70 & $\begin{array}{l}\text { 2-Methylfuran } \\
\text { 5-Methyl-2-nitrofuran } \\
\quad 2.48(\mathrm{~s}), \mathrm{CH}_{3} ; 6.30(\mathrm{~d}), \mathrm{H}_{4}, J=3.4 \text {; } \\
\quad \text { 7.26(d), } \mathrm{H}_{3}, J=3.4\end{array}$ & $\begin{array}{r}14 \\
6\end{array}$ \\
\hline 2,5-Dinitrofuran & 70 & $\begin{array}{l}\text { 5-Methyl-2-nitrofuran } \\
\text { 2.47(s), } \mathrm{CH}_{3} ; 6.33(\mathrm{~d}), \mathrm{H}_{4}, J=3.4 \\
\text { 7.28(d), } \mathrm{H}_{3}, J=3.4\end{array}$ & 24 \\
\hline 5-Nitro-2-carbomethoxyfuran & 70 & $\begin{array}{l}\text { 5-Methyl-2-carbomethoxyfuran } \\
2.38(\mathrm{~s}), \mathrm{CH}_{3} ; 3.88(\mathrm{~s}), \mathrm{OCH}_{3} ; \\
6.13(\mathrm{~m}), \mathrm{H}_{4} ; 7.10(\mathrm{~d}), \mathrm{H}_{3}, J=3.4 \\
\gamma \text {-Carbomethoxy- } \alpha, \beta \text {-dehydro- } \gamma \text { - } \\
\text { valerolactone } j \\
\text { 1.71(s), } \mathrm{CH}_{3} ; 3.80(\mathrm{~s}), \mathrm{OCH}_{3} ; \\
6.16(\mathrm{~d}), \mathrm{H}, J=5.9 ; 7.48(\mathrm{~d}) \\
\mathrm{H}, J=5.9 \\
\text { 4-Methyl-5-nitro-2-carbomethoxyfuran } \\
2.51(\mathrm{~s}), \mathrm{CH}_{3} ; 3.97(\mathrm{~s}), \mathrm{OCH}_{3} ; \\
7.18(\mathrm{~m}), \mathrm{H}_{3}\end{array}$ & 4 \\
\hline
\end{tabular}

Acta Chem. Scand. 25 (1971) No. 6 
Table 1. Continued.

Thiazole

2-Nitrothiophene (phenylation) $60^{g}$

2-Methylthiazole

2.73(d), $\mathrm{CH}_{3}, J=1.3 ; 7.26(\mathrm{~d}), \mathrm{H}_{5}, J=3.3$;

$7.72(\mathrm{~d}), \mathrm{H}, J=3.3$

5-Methylthiazole

2.52(s), $\mathrm{CH}_{3} ; 7.63(\mathrm{~d}), \mathrm{H}_{4}, J=1.3$;

8.65(s), $\mathrm{H}$

2,5-Dimethylthiazole

2.44(s), $\mathrm{CH}_{3} ; 2.68(\mathrm{~s}), \mathrm{CH}_{3} ; 7.32(\mathrm{~s}), \mathrm{H}_{4}$

60

2-Nitro-3-phenylthiophene

7.02(d), $\mathrm{H}_{4}, J=5.4 ; 7.46(\mathrm{~s}), \mathrm{C}_{6} \mathrm{H}_{5}$;

7.48(d), $\mathrm{H}_{5}, J=5.4$

2-Nitro-5-phenylthiophene

7.23(d), $\mathrm{H}_{4}, J=4.1 ; 7.38-7.68(\mathrm{~m})$,

$\mathrm{C}_{6} \mathrm{H}_{5} ; 7.90(\mathrm{~d}), \mathrm{H}_{3}, J=4.1$

${ }^{a}$ Chloroform was used as solvent, unless otherwise stated.

b In all cases, starting material remained in the product mixture.

$c$ With 2 equivalents of $\mathrm{H}_{2} \mathrm{O}_{2}$ and at $40^{\circ}$, the total yield was about $20 \%$.

$d$ The yield was lower at $60^{\circ}$.

- The yield was very low at $40^{\circ}$.

$f$ After esterification with diazomethane.

$g$ In presence of 0.2 equiv. sulfuric acid.

Acetonitrile- $d_{3}$ was used as solvent.

i After $\mathrm{H}-\mathrm{D}$ exchange.

$i$ Decomposes on standing.

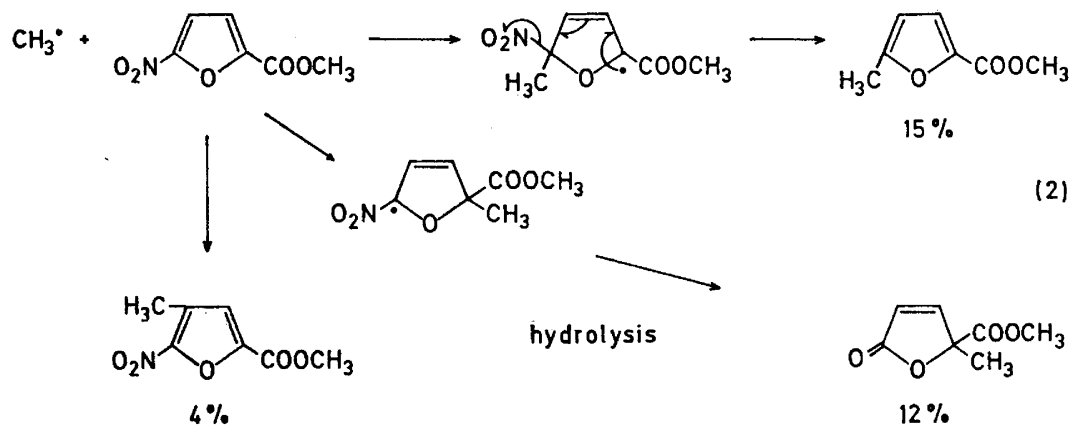

The NMR spectrum is in good agreement with the structure given; $c f$. Table 1. The olefinic protons of, e.g., $\alpha, \beta$-dehydrobutyrolactone are located at $\delta=6.15(\mathrm{~d}, J=5.8 \mathrm{cps})$ and at $\delta=7.63(\mathrm{~d}, J=5.8 \mathrm{cps}) .^{8}$

In the mass spectrum, the molecular peak was very weak, and the fragmentation pattern was difficult to analyse, but not inconsistent with the given structure.

2-Furoic acid was methylated in the 5-position ${ }^{1}$ in a yield of $50 \%$, and 3 -furoic acid gave the 2 -methyl derivative $(18 \%)$. In agreement with earlier experiences, ${ }^{4}$ it was thus found that radicals attack the furan nucleus preponderantly in the 2 - and 5-positions.

Acta Chem. Scand. 25 (1971) No. 6 
2-Nitropyrrole gave two products: 5-methyl- $(30 \%)$ and 3,5-dimethyl-2nitropyrrole $(12 \%)$. Protonation of the substrate facilitated the radical attack, an effect that has also been noted with pyridine and quinoline. ${ }^{4}$

Thiazole was methylated mainly in the 2-position $(14 \%)$, in agreement with earlier findings. ${ }^{9}$

\section{EXPERIMENTAL}

2-Nitrothiophene, ${ }^{10}$ 3-nitrothiophene, ${ }^{11}$ 2-nitropyrrole, ${ }^{12}$ 2-nitrofuran, ${ }^{13}$ and 5-nitro-2carbomethoxyfuran ${ }^{14}$ were prepared according to literature. 3-Furoic acid was supplied by Professor S. Gronowitz, University of Lund, and 2,5-dinitrofuran by Pharmacia AB, Uppsala.

NMR data were obtained with a Varian A-60 spectrometer. IR spectra were recorded on a Perkin Elmer 257 instrument. Mass spectra were run on a Perkin Elmer 270 Mass Spectrometer. The products were preparatively separated on a Varian 1500 gas chromatograph, using silicon SE-52 (20\% on chromosorb) and Porapak Q columns.

General procedure for methylation. $2 \mathrm{mmol}$ of the substrate and $0.4 \mathrm{mmol}$ ferrous sulfate heptahydrate were dissolved in $3 \mathrm{ml}$ dimethyl sulfoxide. An ice-cooled solution of 6 mmol of hydrogen peroxide $(35 \%)$ in $2 \mathrm{ml}$ dimethyl sulfoxide was added to the wellstirred mixture at $60^{\circ} \mathrm{C}$ for a period of $15 \mathrm{~min}$. After standing for another $15 \mathrm{~min}$ at this temperature, the reaction mixture was poured into ice-water and extracted with chloroform $(3 \times 10 \mathrm{ml})$. The chloroform layer was washed with water twice, dried over anhydrous magnesium sulfate, filtered, and evaporated. The residue was analyzed by GLC and NMR, and the structures of the compounds were determined by comparison with authentic material and from NMR spectral evidence.

In the case of the highly reactive 2 -nitropyrrole (sulfuric acid present), the reaction temperature must not exceed $30^{\circ} \mathrm{C}$.

When 2-nitropyrrole and thiazole were methylated in acidic medium, the reaction mixture was made slightly alkaline before the working-up procedure. No attempt was made to optimize the yield in other runs than those with 2-nitrothiophene and 2-furoic acid.

Phenylation of 2-nitrothiophene. A solution of benzenediazonium fluoborate $(0.96 \mathrm{~g}$, $5 \mathrm{mmol})$ and 2-nitrothiophene $(0.65 \mathrm{~g}, 5 \mathrm{mmol})$ in sulfolane $(4 \mathrm{ml})$ was stirred under nitrogen at $60^{\circ}$ for $6 \mathrm{~h}$. The mixture was poured into water, and extracted three times with ether. The ether extract was washed with water repeatedly, dried, filtered, and evaporated. The residue was analysed quantitatively by GLC on a SE-52 column at $240^{\circ} \mathrm{C}$.

Preparative GLC was used for the separation of the products. The thiazole derivatives were collected from the Porapak $Q$ column at $150^{\circ} \mathrm{C}$. The same column was used to separate the 2-methyl-3-carbomethoxyfuran from 3-carbomethoxyfuran at $120^{\circ} \mathrm{C}$. In the other cases, the SE-52 column was used at temperatures ranging from 90 to $210^{\circ} \mathrm{C}$.

Acknowledgement. We are grateful to Profs. S. Gronowitz and A.-B. Hörnfelt, Dr. B. Östman, and Pharmacia AB for gifts of substances. Mrs. Lena Liedgren has kindly recorded out NMR spectra. This work was supported by a grant from the Swedish Natural Science Research Council.

\section{REFERENCES}

1. Bertilsson, B.-M., Gustafsson, B., Kühn, I. and Torssell, K. Acta Chem. Scand. 24 (1970) 3590 .

2. Melander, L. Arkiv Kemi 11 (1957) 397.

3. Camaggi, C. M., Leardini, R., Tiecco, M. and Tundo, A. J. Chem. Soc. B 1969 1251 , and references therein.

4. Norman, R. O. C. and Radda, G. K. Advan. Heterocycl. Chem. 2 (1963) 131.

5. Shelton, J. R. and Uzelmeier, C. W. Rec. Trav. Chim. 87 (1968) 1211.

6. Engelsma, J. W. and Kooyman, E. C. Rec. Trav. Chim. 80 (1961) 537.

Acta Chem. Scand. 25 (1971) No. 6 
7. Nakanishi, K. Infrared Absorption Spectroscopy, Nankodo, Tokyo 1962.

8. Varian Spectra Catalogue I, 1962, No. 51.

9. Dou, H. J. M. Bull. Soc. Chim. France 19661678.

10. Östman, B. Acta Chem. Scand. 22 (1968) 1687.

11. Blatt, A. H., Bach, S. and Kresch, L. W. J. Org. Chem. 22 (1957) 1694.

12. Anderson, H. J. Can. J. Chem. 35 (1957) 21.

13. Mndjoyan, A. L. Sin. Geterotsikl. Soedin 8 (1969) 56.

14. Freure, B. T. and Johnson, J. R. J. Am. Chem. Soc. 53 (1931) 1142.

Received November 6, 1970. 